\title{
Intradimensional and extradimensional shift learning by pigeons'
}

\section{N. J. MACKINTOSH and LYDIA LITTLE, Dalhousie University, Halifax, Nova Scotia, Canada}

Pigeons were trained consecutively on two simultaneous visual discriminations. For half the Ss, the dimension relevant in the first problem remained relevant in the second (intradimensional shift); for the remainder, the dimension irrelevant in the first problem became relevant in the second (extradimensional shift). As is predicted by two-stage theories of discrimination learning, the intradimensional shift was learned more rapidly than the extradimensional shift.

Several recently proposed theories of discrimination learning have assumed that in order to solve a discrimination problem, Ss must not only learn which value of the relevant dimension is associated with reinforcement, but must also learn to identify, observe, or attend to the relevant dimension itself (Lovejoy, 1968; Sutherland, 1964; Zeaman \& House, 1963). One prediction that follows from such a theory is that training on one problem with a given dimension relevant may selectively facilitate the learning of a new discrimination problem involving the same relevant dimension even though no direct transfer based on the response requirements of the two tasks could be expected. Lawrence's experiments on the acquired distinctiveness of cues, in which transfer between successive and simultaneous discriminations was assessed, provided the earliest support for this prediction (Lawrence, 1949); but the procedure has since been criticized by Siegel (1967) on the grounds that some direct transfer might have occurred.

A second appropriate experimental design, used in studies of human concept learning, involves comparing intradimensional shift (IDS) and extradimensional shift (EDS) learning. Ss are trained on a discrimination problem with Dimension $A$ relevant and Dimension $B$ irrelevant; in the second stage of the experiment new values of the two dimensions are chosen, and Ss learning the IDS problem are again trained with $A$ relevant and $B$ irrelevant, while Ss learning the EDS problem are trained with $B$ relevant and $A$ irrelevant. If Ss during Stage 1 learn to attend to $A$ and ignore $B$, and if these attentional changes transfer to the new values of A and B used in Stage 2, then the IDS problem should be learned more rapidly than the EDS problem.

Although there is ample evidence that human Ss, from 4year-old children (Trabasso, Deutsch, \& Gelman, 1966) to college students (Isaacs \& Duncan, 1962) learn IDS problems more rapidly than EDS problems, only one study with animals (rats) has shown such an effect (Shepp \& Eimas, 1964). The present experiment was designed to see whether pigeons would show any difference in rate of learning the two kinds of problems.

\section{SUBJECTS}

The Ss were 16 White Carneaux pigeons, six months old. They were maintained at $80 \%$ of their ad lib weights.

\section{APPARATUS}

The apparatus was a three-key pigeon chamber, with the center key blacked out except during initial shaping. The stimuli were projected onto the rear of the two side keys by means of in-line projectors, and consisted of three colored lines on a white background. The colors were red, yellow, green, or blue; and the orientation of the lines was $0,90,45$, or $135 \mathrm{deg}$.

\section{PROCEDURE}

After being shaped to peck at a white center key, Ss were given 50 noncorrection trials each day for the remainder of the experiment. At the beginning of each trial, the house light was turned off and the two side keys were illuminated. A correct response led to $5-\mathrm{sec}$ access to grain; an error led to 8 -sec time-out in darkness. At the end of each trial, the house light was turned on and a 25 -sec intertrial interval followed. All events were controlled by external programming equipment, and responses were recorded on counters.

\section{EXPERIMENTAL DESIGN}

All Ss learned two simultaneous discriminations. In Stage 1, the stimuli were red and yellow, 0-deg and 90-deg lines. For eight Ss, color was the relevant dimension (half being trained with red positive, half with yellow positive), and orientation irrelevant. For the remaining Ss, orientation was relevant (0-deg positive for half, 90-deg positive for the other half) and color was irrelevant. The position of the positive and negative stimuli, and the values of the irrelevant dimension, were determined by selected Gellermann orders. All Ss received 250 trials.

In Stage 2, the stimuli were blue and green, 45-deg and 135-deg lines. Half of each of the above groups was trained on a color problem (blue positive) with orientation irrelevant, and half was trained on an orientation problem (45-deg positive) with color irrelevant. All Ss were trained to a criterion of 40 correct responses in a day.

There were, therefore, four main experimental groups distinguished by the dimensions relevant in Stages 1 and 2: Color-color, and orientation-orientation (these groups learned an IDS problem in Stage 2); color-orientation, and orientation-color (these groups learned an EDS problem in Stage 2). Within these four groups, equal numbers of Ss had been trained in opposite directions in Stage 1.

\section{RESULTS}

Table 1 shows the average number of errors made during the 250 trials of Stage 1. The color discrimination was substantially easier than the orientation discrimination $(F=42.71, \mathrm{df}=1 / 12, \mathrm{p}<.001)$, but Ss subsequently learning EDS and IDS problems were closely matched for Stage-1 scores $(F<1)$. All Ss achieved a criterion of 40 correct responses in a day.

Table 1 also shows the number of errors to criterion in Stage 2. Again, the color discrimination was casier than the orientation discrimination $(F=49.67, \mathrm{df}=1 / 12, \mathrm{p}<.001)$. The IDS problem was learned faster than the EDS problem $(F=5.67, \mathrm{di}=1 / 12, \mathrm{p}<.05) ;$ and there was no interaction between dimensions and type of shift $(F<1)$. Finally there was little sign of any direct (response-based) transfer between the two problems. Of the eight Ss that learned color in Stage 1 , those trained with red positive selected blue on $64.5 \%$ of trials on the first day of Stage 2, while those trained with yellow positive selected blue on $54 \%$ of trials. Similarly, of the

\begin{tabular}{lcc} 
Groups & Table 1 & \\
& $\begin{array}{r}\text { Stage 1 } \\
\text { Errors in 250 Trials }\end{array}$ & $\begin{array}{c}\text { Stage 2 } \\
\text { Errors } \\
\text { to Criterion }\end{array}$ \\
\hline Color & 25.25 & 13.50 \\
ion - Color & 77.50 & 30.50 \\
& & \\
ion - Orientation & 74.75 & 54.00 \\
Orientation & 24.50 & 67.00 \\
\hline
\end{tabular}


Ss trained on orientation in Stage 1, those trained with 0 deg positive selected the 45 -deg lines on $58.5 \%$ of trials, while those trained with 90 deg positive selected the 45 -deg lines on $50 \%$ of trials. Neither of these differences approached significance (in both cases, $p>.20$ ).

In conclusion, therefore, pigeons, like rats and humans, learn IDS problems faster than EDS problems. Although the effect was a relatively small one, the results suggest that transfer between problems may occur which cannot be explained simply in terms of differential response tendencies. It appears that learning to attend to the relevant dimension is part of what is involved in learning a discrimination problem.

\section{REFERENCES}

ISAACS, I. D., DUNCAN, C. P. Reversal and nonreversal shifts within and between dimensions in concept formation. Journal of Experimental Psychology, 1962, 64, 580-585.
LAWRENCE, D. H. Acquired distinctiveness of cues: I. Tranafer between discriminations on the basis of familiarity with the stimulus. Joumal of Experimeatal Pxycholoty, 1949, 39, 770-784.

LOVEJOY, E. Attention th discrimination leaming. San Francisco: Holden-Day, 1968.

SHEPP, B. E., EIMAS, P. D. Intradimenaional and extradimensional shifts in the rat. Journal of Comparative \& Physiological Psychology, $1964,57,357-361$.

SIEGEL, S. Overtraining and transfer proceses. Journal of Comparative \& Physiolodical Psycholozy, 1967, 64, 471-477.

SUTHERLAND, N. S. The learning of discriminations by animals. Endeavour, 1964, 23, 148-152.

TRABASSO, T., DEUTSCH, J. A., GELMAN, R. Attention in discrimination learning of young children. Journal of Experimental Child Psychology, 1966, 4, 9-19.

ZEAMAN, D., \& HOUSE, B. J. The role of attention in retardate discrimination karning. In N. R. Ellis (Ed.), Handbook of mental deficiency: Prychological theory and research. New York: McGrawHill, 1963. Pp. 159-223.

\section{NOTE}

1. This research was supported by Grant APA-259 from the National Research Council of Canada.

\section{(Continued from page 4)}

reported limited success with unconditioned locomotory responses to light (Loeb, 1893; Cole, 1922; Northrup \& Loeb, 1923; Wolf \& Zerrahn-Wolf, 1937; Waterman, 1953; von Campenhausen, 1966), but these responses appear to vary uncontrollably. with a myriad of variables, including the emotional state of the animal (Cole, 1923). In order to achieve some consistent control over the animal, avoidance conditioning was attempted.

Method

A modified shuttlebox was made out of a plastic tray $12 \mathrm{x}$ 14 in. with just enough sea water in it to permit juveniles to swim. A sufficient dc potential could be applied between two carbon rods spanning opposite ends of the tray to cause $S$ to swim in the direction away from the anode. $S$ was given $10 \mathrm{sec}$ after onset of one of two light sources at opposite ends of the tray, in order to approach (or avoid, in some cases) the light. If, at the end of that time $S$ was not in the correct end of the tray, a potential was applied across the tank that was of sufficient voltage and in the direction necessary to drive $S$ into the correct end of the tray. This was kept on until $S$ actually had moved to the correct location. Light sources and hence correct ends of the tray varied randomly, independently of the location of $S$ so that mere light-contingent activity did not serve to avoid the shock.

Because this response conflicted with a phototaxis, it was necessary to move the lights to the sides of the tray at right angles to the direction of movement required of $S$, after 200 trials. The training with the direct approach or avoidance of the light seemed necessary for $S$ to "learn" the complicated response of determining the correct end of the tray on the basis of which side of the tray the source was on.

Results

A response was defined as a crossing from one end of the tray to the other, in either direction. Passive avoidances, or passive failures to avoid were not counted as responses. Responses occurred on $20 \%$ of the trials. Of these, $60 \%$ were in the correct direction, when $50 \%$ was expected by chance alone. More active Ss did no better than inactive ones.

Although "conditioned" responses thus occurred on only about $1 \frac{1}{2}$ to $2 \%$ of the trials, any level of significance could be obtained by running enough trials; $t$-scores greater than 12 were obtained for individuals, and it was possible to generalize, on the basis of the five Ss used in the last experiment, to the population of Ss at the 0.05 level.
Two Ss showed, in addition to the instrumental responses, statistically significant phototaxic behavior during the conditioned stimulus, one positive in sign, the other negative. Four of the five Ss showed very strong phototaxic behavior during shock (up to $90 \%$ in the same direction), but again two were positive and two negative in sign.

\section{DISCUSSION}

The significance and utility of any of the behaviors studied here is at best marginal. They are not, however, out of line with previous results from other invertebrates (Warren, 1965). The most promising line of investigation probably is to instrument general activity in the "shuttle-tray," for observation of $S$ during avoidance training gave a distinct impression that $S$ anticipated the shock although being unable to respond appropriately to it very often.

\section{REFERENCES}

BULLOCK, T. H. (Ed.) Simple systems for the study of learning mechanisms. Neurosciences Research Program Bulletin, 1966, 4, 105-233.

COLE, W. H. Circus movements of Limulus and the tropism theory. Journal of General Physiology, 1922, 5, 417-426.

COLE, W. H. Effect of laboratory age upon the phototropic reactions of Limulus. Journal of General Physiology, 1923, 6, 295-297.

CORNING, W. C., FEINSTEIN, D. A., \& HAIGHT, J. M. Arthropod preparation for behavioral, electrophysiological, and biochemical studies. Science, 1965, 148, 394-395.

LOEB, J. Über kuenstliche Umwandlung positiv heliotropischer Thiere in negativ heliotropische und umgekehrt. Archiv für die Gesamte Psy chologie, 1893, 54, 81-107.

NORTHRUP, J. H., \& LOEB, J. The photochemical basis of animal heliotropism. Journal of General Physiology, 1923, 5, 581-595.

SMITH, J. C., BAKER, H. D. Conditioning in the horseshoe crab. Journal of Comparative \& Physiological Psychology, 1960, 53, 279-281.

von CAMPENHAUSEN, $C$. The ability of Limulus to see visual patterns. Journal of Experimental Biology, 1967, 46, 557-570.

WARREN, J. M. The comparative psychology of learning. Annual Review of Psychology, 1965, 16, 95-118.

WOLF, E., \& ZERRAHN-WOLF, G. Reactions of Limulus to illuminated fields of different areas and flicker frequency. Journal of General Physiology, 1937, 20, 767-776.

\section{NOTE}

1. This research was done while the author was on the staff of the IBM Research Center, Yorktown Heights, N. Y. Analysis of the data and writing were partially supported by U. S. Public Health Service Grants MH14955-01 and NB08070-01. The author is indebted to Jean Kirby for her assistance. 